\title{
Iron Metabolism, Hemolytic Anemia, and Thalassemia
}

\author{
Deepak Bansal ${ }^{1} \cdot$ Ashutosh Lal $^{2}$ (B)
}

Received: 3 December 2019 / Accepted: 3 December 2019 / Published online: 11 December 2019

(C) Dr. K C Chaudhuri Foundation 2019

This issue of the Journal begins a two-part symposium on the subject of benign hematology. Six articles will be presented in two consecutive issues to address a wide range of disorders that are of vital importance to the practicing pediatrician or hematologist. The significance of these disorders is diminished by the term "benign," which is misleading. While the disorders are not malignant or cancerous, they are associated with serious morbidity and affect the quality of life of millions of individuals of all ages. The inherited forms of these disorders, such as thalassemias, sickle cell disease and glucose-6phosphate dehydrogenase deficiency, are the most common single-gene disorders in humans observed in 5 lac new births annually. The inherited and acquired bleeding or thrombotic diatheses are frequently encountered as primary entities or complicating a concurrent illness that requires expert clinical and laboratory management. Nutritional anemia is a vast public health crisis that cannot be solved without advocacy by the national physician associations.

In the first review, the complex topic of iron metabolism has been simplified [1]. In the last two decades, there have been significant advances in understanding iron biology and greater insight into diseases associated with altered iron balance. The magnitude of iron deficiency among women and children remains an intractable challenge. A dedicated implementation of the Anemia Mukt Bharat - Intensified Iron-plus Initiative Program of the Govt. of India is a long-awaited necessity to overcome the high prevalence of iron deficiency anemia in the country [2]. Iron deficiency results in adverse neurocognitive and developmental outcomes in the

Ashutosh Lal

Ashutosh.Lal@ucsf.edu

1 Pediatric Hematology-Oncology Unit, Department of Pediatrics, Advanced Pediatrics Center, Postgraduate Institute of Medical Education and Research, Chandigarh, India

2 UCSF School of Medicine, Director, Thalassemia Program, Hematology/Oncology, UCSF Benioff Children's Hospital Oakland, 747 52nd Street, Oakland, CA 94609, USA developing brain. Every pediatrician should self-educate the recommendations of the Iron-plus Initiative Program. The pediatricians owe it to the children of the country to reassure and reinforce the parents regarding the prophylactic supplementation of iron to all children and adolescents from 6 mo till $19 \mathrm{y}$ of age [2]. The American Academy of Pediatrics recommends universal iron supplementation for term, breastfed infants from 4 mo of age [3]. The policymakers in India should deliberate if iron supplementation should be recommended at 4 mo instead of the current practice of $6 \mathrm{mo}$, in predominantly breastfed, 'healthy babies' $[4,5]$.

Understanding the hepcidin-ferroportin axis and its regulation has inspired the development of novel therapeutic strategies for managing disorders of iron deficiency or overload [6, 7]. However, much remains to be learned from the perspective of India, particularly the interaction of environmental influences on common polymorphisms in populations where dietary iron availability is limited [1].

In the second review, Jamwal et al. have elaborated on the laboratory diagnosis of hemolytic anemia [8]. Investigating the etiology of hemolytic anemia can seem daunting in the busy out-patient. However, a step-by-step approach is fruitful in the vast majority. The ethnicity may sometimes be a clue to the etiology in disorders such as thalassemia, sickle cell disease, and hereditary spherocytosis, etc [9]. A clinical picture suggestive of thalassemia with unremarkable hemoglobin electrophoresis in some communities can be an indication to investigate for congenital dyserythropoietic anemia $[10,11]$. Attention to clinical detail and close cooperation with the pathologist or the laboratory hematologist is essential for arriving at a diagnosis. An examination of peripheral smear performed by an experienced pathologist, who has been communicated the clinical details of the patient by the pediatrician, is the critical step to direct the specific diagnostic investigations. Reticulocyte count aids in narrowing the differential diagnosis. A high reticulocyte count is typically observed in membrane or enzyme disorders, immune hemolytic anemia and unstable hemoglobin. With a background of the triad of anemia, splenomegaly, and unconjugated hyperbilirubinemia, a 
low reticulocyte count suggests dyserythropoietic anemia, such as beta or alpha thalassemia, sideroblastic anemia or congenital dyserythropoietic anemia. In clinical practice, the reticulocyte count is often observed to be suppressed after a red cell transfusion, and retesting after several weeks is helpful. Increasingly affordable access to next-generation sequencing should aid in the diagnosis of some of the complex hemolytic anemias [8].

In the third review of the hematology symposium, we have addressed common clinical queries in the management of thalassemia [12]. It is not uncommon to ponder if a patient should best be treated as beta-thalassemia major (TM) or as a nontransfusion-dependent thalassemia (NTDT). The authors recommend that the diagnosis of TM or NTDT should not be based on a one-time assessment. Several patients have chronic anemia that is not severe enough to justify regular transfusions. However, the clinical course can evolve with age. Continued follow-up may divulge that some patients who are considered NTDT will benefit from transfusions later in life. The common errors observed in the management of TM include, a) Not maintaining an optimal pre-transfusion hemoglobin according to the Thalassemia International Federation recommendation of 9.0 to $10.5 \mathrm{~g} / \mathrm{dl}$ [13], b) Inclination to transfuse one instead of two units of red cells in patients with TM weighing $>30 \mathrm{~kg}$, and c) Waiting needlessly for the red cell unit to attain room temperature.

Pediatric Oncology, including malignant hematology, tends to weigh over the practice of benign hematology. Yet, pediatricians are much more likely to encounter benign hematology disorders in their day-to-day practice. This symposium is an attempt to highlight the fascinating and rewarding field of benign hematology.

\section{Compliance with Ethical Standards}

Conflict of Interest None.

\section{References}

1. Lal A. Iron in health and disease: an update. Indian J Pediatr. 2019. https://doi.org/10.1007/s12098-019-03054-8.

2. Anemia Mukt Bharat. Available at: https://anemiamuktbharat.info/. Accessed 30 November 2019.

3. Baker RD, Greer FR; Committee on nutrition American Academy of Pediatrics. Diagnosis and prevention of iron deficiency and iron deficiency anemia in infants and young children (0-3 years of age). Pediatrics. 2010;126:1040-50.

4. Krishnaswamy S, Bhattarai D, Bharti B, Bhatia P, Das R, Bansal D. Iron deficiency and iron deficiency anemia in 3-5 months-old, breastfed healthy infants. Indian J Pediatr. 2017;84:505-8.

5. Bansal D. Iron deficiency in India. Indian J Pediatr. 2016;83:615-6.

6. Lal A, Atamna W, Killilea DW, Suh JH, Ames BN. Lipoic acid and acetyl-carnitine reverse iron-induced oxidative stress in human fibroblasts. Redox Rep. 2008;13:2-10.

7. Bansal D. Hepcidin and thalassemia. Indian J Pediatr. 2017;84: 731-2.

8. Jamwal M, Sharma P, Das R. Laboratory approach to hemolytic anemia. Indian J Pediatr. 2019. https://doi.org/10.1007/s12098019-03119-8.

9. Das A, Bansal D, Das R, Trehan A, Marwaha RK. Hereditary spherocytosis in children: profile and post-splenectomy outcome. Indian Pediatr. 2014;51:139-41.

10. Singleton B, Bansal D, Varma N, et al. Homozygosity mapping reveals founder SEC23B-Y462C mutations in Indian congenital dyserythropoietic anemia type II. Clin Genet. 2015;88:195-7.

11. Marwaha RK, Bansal D, Trehan A, Garewal G, Marwaha N. Congenital dyserythropoietic anemia: clinical and hematological profile. Indian Pediatr. 2003;40:551-5.

12. Lal A, Bansal D. Thalassemia: common clinical queries in management. Indian J Pediatr. 2019. https://doi.org/10.1007/s12098-01903065-5.

13. Trompeter S, Cohen A. Blood transfusion. In: Cappellini MD, Cohen A, Porter J, Taher A, Viprakasit V, editors. Guidelines for the Management of Transfusion Dependent Thalassemias (TDT), 3rd ed. Cyprus: Thalassemia International Federation; 2016. p. 2841.

Publisher's Note Springer Nature remains neutral with regard to jurisdictional claims in published maps and institutional affiliations. 